\title{
Increased upper airway cytokines and oxidative stress in severe obstructive sleep apnoea
}

\author{
R.J. Kimoff*,", Q. Hamid*, M. Divangahi*, S. Hussain*,\#, W. Bao*, \\ N. Naor ${ }^{\#}$, R.J. Payne ", A. Ariyarajah*, K. Mulrain* and B.J. Petrof*,
}

ABSTRACT: Inflammation may contribute to upper airway pathophysiology in obstructive sleep apnoea (OSA). Our objective was to compare upper airway pro-inflammatory cytokine expression, oxidative stress and connective tissue deposition in severe $(n=25)$ versus mild $(n=17)$ OSA patients.

Upper airway surgical specimens were separated by predominance of either mucosal or muscle tissue. Expression levels of interleukin (IL)-1 $\alpha$, IL-6, interferon- $\gamma$, RANTES (regulated on activation, normal T-cell expressed and secreted), transforming growth factor (TGF)- $\beta$ and L-selectin were measured by ribonuclease protection assay. Oxidative stress was assessed via protein carbonyl group detection by immunoblotting. Histochemistry was employed for immunolocalisation of selected cytokines and connective tissue morphometry.

In the severe OSA group, expression of IL-1 $\alpha$, IL-6 and TGF- $\beta$ was significantly higher in mucosa-predominant tissues, whereas in muscle-predominant specimens, RANTES expression was greater in severe OSA. Increased protein carbonylation was observed in severe OSA within both mucosal and muscle compartments. Immunohistochemistry localised TGF- $\beta$ to submucosal and perimuscular inflammatory cells, while IL-6 was primarily localised to myocytes. Consistent with the pro-fibrotic cytokine profile observed in mucosa-predominant tissue, morphometric analysis revealed greater submucosal and perimuscular connective tissue in severe OSA subjects.

There is increased pro-inflammatory and pro-fibrotic cytokine expression, oxidative stress, and connective tissue deposition in upper airway tissues from severe versus mild OSA patients.

KEYWORDS: Cytokine, fibrosis, inflammation, obstructive sleep apnoea, oxidative stress

$\mathbf{T}$ here is growing evidence that systemic $[1,2]$ and upper airway $[1,3-5]$ inflammation are increased in obstructive sleep apnoea (OSA). Upper airway inflammation in OSA may be related to mechanical trauma and/ or increased tissue oxidative stress $[1,4,6]$. Inflammatory markers are increased in induced sputum, exhaled breath condensate and nasal lavage specimens in OSA [1, 3, 7-10]. There is also increased inflammatory cell infiltration within upper airway tissue $[4,11,12]$. We reported differences in inflammatory cell subsets within the mucosal versus muscular compartments of palatal tissue in OSA [4], suggesting that the inflammatory process may differ between upper airway tissue compartments.

Altered tissue mechanics and neuromuscular function are clearly important factors in the pathophysiology of OSA [13]. Exposure of upper airway tissues to pro-inflammatory mediators, such as cytokines and reactive oxygen species, could alter tissue structure and function, and impair skeletal muscle contractility [14-16]. Moreover, sustained exposure to certain cytokines can lead to fibrosis, which could adversely affect upper airway collapsibility through changes in tissue compliance and/or mechanical coupling of dilator muscles [12, 17-21]. Therefore, evaluation of pro-inflammatory mediators within upper airway tissues of OSA patients may provide new insights into the mechanisms underlying inflammation as well as the potential sequelae for upper airway tissue structure and function.

The primary objective of this study was to compare levels of cytokine/chemokine expression and oxidative stress present within upper airway tissues obtained from severe versus mild OSA patients. We hypothesised that severe OSA
AFFILIATIONS

*Meakins-Christie Laboratories, McGill University,

${ }^{\#}$ Respiratory Division and Sleep Laboratory, McGill University Health Centre, and

"Dept of Otolaryngology, McGill University Health Centre, Montreal, QC, Canada.

CORRESPONDENCE

R.J. Kimoff

Respiratory Division

Room L4.08

McGill University Health Centre

687 Pine Ave W.

Montreal

QC

H3A 1 A1

Canada

E-mail: john.kimoff@mcgill.ca

Received:

March 262010

Accepted after revision:

Sept 072010

First published online:

Sept 162010 
would be associated with: 1) higher levels of pro-inflammatory and/or pro-fibrotic cytokine expression; 2) increased oxidative stress; and 3) greater connective tissue deposition within upper airway structures. We further hypothesised that the proinflammatory mediator profile would differ between the mucosal versus muscular compartments of the upper airway.

\section{METHODS \\ Subjects}

Adults with untreated OSA scheduled to undergo upper airway surgery for OSA were recruited from the McGill University (Montreal, QC, Canada) system. Subjects had either an apnoea/hypopnoea index of 10-25 (mild group) or $>40$ events $\cdot \mathrm{h}^{-1}$ (severe group) on an overnight polysomnogram performed within 8 weeks of surgery. Exclusion criteria included previous upper airway surgery (excluding remote tonsillectomy), active smoking, oral or inhaled anti-inflammatory medication, upper respiratory tract infection within 8 weeks, diabetes, or any known neuromuscular disease or inflammatory condition. This study was approved by our Research Ethics Board, and informed consent was obtained from all subjects.

\section{Polysomnography}

Diagnostic polysomnography was performed as previously described either in the sleep laboratory (Sandman; Tyco Inc., Ottawa, Canada) [4] or at home (Suzanne portable complete polysomnography device; Tyco Inc.) [22]. The same signals were recorded during both types of studies and analysis was performed on the same computerised system (Sandman version 6.2) using identical scoring criteria. Polysomnographic recordings had to conform to "very good" or "excellent" recording quality criteria as previously described [22] and show a total sleep time of $>4 \mathrm{~h}$. Sleep-wake state and arousals were scored using conventional criteria $[23,24]$ and respiratory events were scored according to the Chicago criteria [25]. Standard measures of sleep structure, respiratory disturbance and oxygenation were derived as previously described $[4,22]$ for correlation with tissue findings.

\section{Surgical tissue procurement}

Patients underwent conventional uvulopalatopharyngoplasty (UPPP) and/or tonsillectomy. The time of surgery was dictated by the clinical operating room schedule, with procurement typically occurring between 10:00 and 14:00 h. There was no systematic difference in morning versus afternoon harvesting between the mild and severe groups. Tissues were excised using a scalpel prior to use of electrocautery in order to avoid burn-related tissue alterations. UPPP specimens consisted of the uvula and contiguous resected palatal tissue. For tonsillectomy specimens, the resection margin included a segment of the anterior tonsillar pillar, which was dissected off the tonsil itself and harvested for analysis. The tonsillar tissue per se was not analysed. A study technologist procured tissues in the operating theatre immediately upon resection. Specimens were oriented in optimal cutting temperature embedding medium, snap-frozen in isopentane and stored at $-80^{\circ} \mathrm{C}$.

\section{Tissue evaluation}

$6-\mu \mathrm{m}$ frozen sections were stained with haematoxylin and eosin to determine tissue content prior to further processing.
Sections with intact squamous epithelium and underlying submucosal connective tissue and mucus glands were identified as "mucosa-predominant", while specimens with $>50 \%$ muscle content were identified as "muscle-predominant", as previously described [4]. The majority of mucosa-predominant samples were uvulopalatal specimens, while the majority of muscle-predominant samples were tonsillar pillars; these proportions were not significantly different for the mild versus severe groups. In addition, although it was not possible to perform all of the gene expression and biochemical analyses in every patient due to limited amounts of tissue, the clinical characteristics and tissue proportions for each subgroup analysis did not differ significantly from those observed in the mild versus severe groups as a whole.

\section{Ribonuclease protection assay}

For RNA extraction, serial frozen sections were processed as previously described [26]. Total RNA was extracted using Trizol reagent (Invitrogen, Burlington, Canada). ${ }^{32} \mathrm{P}$-labelled riboprobes were synthesised using a commercial human multiprobe kit (BD Bioscience; Pharmingen, San Diego, CA, USA) containing templates against gene transcripts for a selected series of cytokines/chemokines known to be involved in leukocyte trafficking, inflammatory responses, tissue repair and fibrosis: RANTES (regulated on activation, normal T-cell expressed and secreted; C-C chemokine ligand 5), L-selectin, interleukin (IL)-1 $\alpha$, IL-6, transforming growth factor (TGF)- $\beta$ and interferon (IFN) $-\gamma$. The riboprobes were hybridised with each RNA sample overnight at $56^{\circ} \mathrm{C}$, using $20 \mu \mathrm{g}$ RNA per sample. Protected RNA fragments were separated using a $5 \%$ polyacrylamide gel and detected using autoradiography. Bands were then quantified using an image analysis system (FluorChem 8000; Alpha Innotech Corp., San Leandro, CA, USA) and the signals normalised to a housekeeping gene (ribosomal protein L32).

\section{Immunocytochemistry}

In order to localise the sites of cytokine expression, immunocytochemistry was performed as previously described [27] using the alkaline phosphatase technique and visualisation with Fast Red (Dako Inc., Glostrup, Denmark). Primary antibodies (mouse anti-human) for IL-6 (Serotec, Kidlington, UK) and TGF- $\beta$ (R\&D Systems, Minneapolis, MN, USA) were used at dilutions of 1:50 and 1:10, respectively. Two sets of control slides were processed in parallel: slides incubated with no primary antibody and slides incubated with a primary mouse antihuman antibody to an irrelevant antigen ("isotype" control).

\section{Detection of protein carbonylation}

Formation of protein carbonyls, a marker of oxidative stress, was assessed by immunoblotting as as previously described [28]. Serial sections of mucosa- and muscle-predominant tissues were homogenised in $6 \mathrm{vol}$ (weight/volume) buffer (10 $\mathrm{mM}$ hydroxyethyl piperazine ethane sulfonic acid, $0.1 \mathrm{mM}$ EDTA, pH 7.4; $1 \mathrm{mM}$ dithiothreitol; $1 \mathrm{mg} \cdot \mathrm{mL}^{-1}$ phenylmethylsulfonyl fluoride; $0.32 \mathrm{mM}$ sucrose; and $10 \mu \mathrm{g} \cdot \mathrm{mL}^{-1}$ each of leupeptin, aprotinin and pepstatin A). Crude homogenates were centrifuged at $4{ }^{\circ} \mathrm{C}$ for $15 \mathrm{~min}$ at $4,500 \times g$ (5,000 rpm). Supernatants were collected for immunoblotting. Protein carbonyls were detected using a commercial kit (Oxyblot Protein Oxidation Detection; Intergen Inc., Purchase, NJ, USA). 


\begin{tabular}{|c|c|c|c|}
\hline & Mild & Severe & p-value \\
\hline Subjects $\mathrm{n}$ & 17 & 25 & \\
\hline Age yrs & $44.8 \pm 3.3$ & $48.5 \pm 2.7$ & NS \\
\hline $\mathrm{BMI} \mathbf{k g} \cdot \mathrm{m}^{-2}$ & $26.5 \pm 1.3$ & $27.4 \pm 1.2$ & NS \\
\hline Neck circumference cm & $38.7 \pm 1.4$ & $41.1 \pm 1.2$ & NS \\
\hline Males/females $\mathbf{n}$ & $14 / 3$ & $23 / 2$ & NS \\
\hline \multicolumn{4}{|l|}{ Polysomnographic data } \\
\hline Total sleep time $\mathrm{h}$ & $5.9 \pm 0.6$ & $5.8 \pm 0.4$ & NS \\
\hline Sleep efficiency \% & $78.9 \pm 5.0$ & $75.1 \pm 3.6$ & NS \\
\hline Respiratory arousal index events $\cdot h^{-1}$ & $9.3 \pm 1.7$ & $41.2 \pm 3.1$ & 0.01 \\
\hline Stage $1 \%$ & $14.2 \pm 2.8$ & $19.8 \pm 5.1$ & NS \\
\hline Stage $2 \%$ & $48.6 \pm 3.6$ & $58.1 \pm 4.3$ & NS \\
\hline Stages $3-4 \%$ & $18.6 \pm 2.8$ & $8.5 \pm 1.8$ & 0.003 \\
\hline REM \% & $17.0 \pm 2.3$ & $13.4 \pm 1.8$ & NS \\
\hline Snoring time min & $24.1 \pm 10.8$ & $75.2 \pm 25.3$ & NS \\
\hline Apnoea index events $\cdot h^{-1}$ & $2.4 \pm 0.6$ & $24.9 \pm 2.7$ & 0.01 \\
\hline Hypopnoea index events $\cdot \mathrm{h}^{-1}$ & $13.7 \pm 1.7$ & $34.6 \pm 4.8$ & 0.02 \\
\hline $\mathrm{AHI}$ events $\cdot \mathrm{h}^{-1}$ & $16.2 \pm 1.6$ & $59.4 \pm 5.0$ & 0.03 \\
\hline Mean $\mathrm{Sa}_{1} \mathrm{O}_{2} \%$ & $96.8 \pm 0.7$ & $92.6 \pm 1.2$ & 0.04 \\
\hline Nadir $\mathrm{Sa}, \mathrm{O}_{2} \%$ & $91.5 \pm 1.2$ & $81.2 \pm 3.2$ & $<0.001$ \\
\hline
\end{tabular}

Aliquots $(15 \mu \mathrm{g})$ of protein were denatured with $12 \%$ sodium dodecylsulfate (SDS); protein side chains were derivatised to 2,4-dinitrophenylhydrazone by reaction with $10 \mu \mathrm{L} 1 \times 2,4-$ dinitrophenylhydrazine, followed by the addition of $7.5 \mu \mathrm{L}$ neutralising solution and 2-mercaptoethanol. Derivatised proteins were separated on $12 \%$ SDS-polyacrylamide gel. Proteins were then transferred to polyvinylidene difluoride membranes, which were blocked and incubated with anti-dinitrophenyl moiety antibody overnight. Following application of horse radish perioxidase-conjugated secondary antibody, densities of protein bands were quantified with an optical densitometer and the optical densities of protein bands were quantified. Loading of equal amounts of proteins was confirmed by stripping the membranes and re-probing with anti- $\alpha$-tubulin antibody (Sigma-Aldrich Co., Oakville, ON, Canada).

\section{Morphometric analysis of connective tissue content}

Frozen sections were stained with van Gieson's stain for connective tissue [27]. Representative fields (five or more per slide) of van Gieson-stained sections were captured using a $10 \times$ microscope objective using a computerised image system (ImagePro Plus; Media Cybernetics, Bethesda, MD, USA). A standardised grid was superimposed on the image and pointcounting was used to identify tissue content. Connective tissue content was expressed as a percentage of the total counts per grid and values are reported as the mean for all grids from a given tissue specimen. Tissue elements included in counts were muscle, vessels, nerve, mucus glands, connective tissue and fat (as fat per se was not preserved/stained in the van Gieson sections, fat was identified in these sections as typical thinrimmed empty vacuoles within tissue). For muscle-predominant
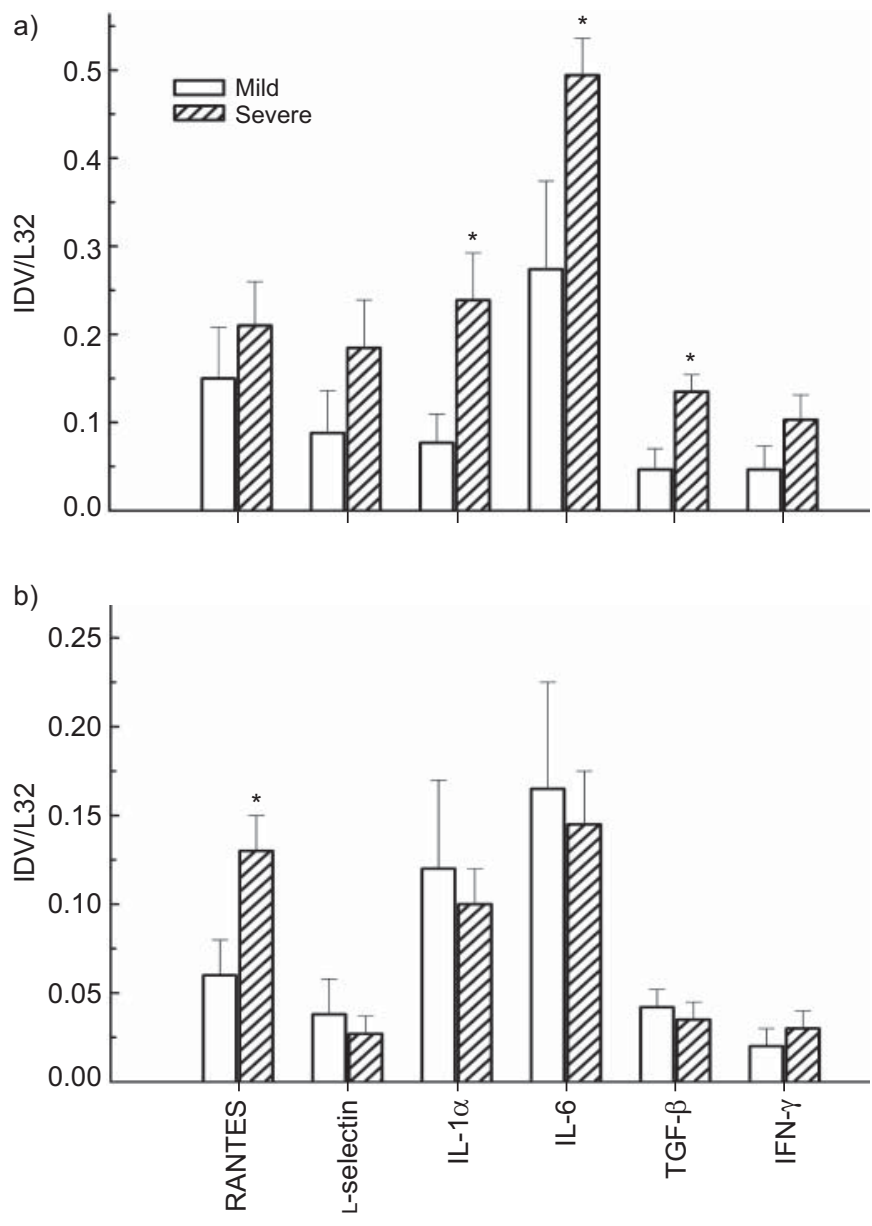

FIGURE 1. Group mean $\pm S E$ for cytokine mRNA levels, normalised to housekeeping gene (L32) expression, for the severe ( $n=17)$ versus mild $(n=10)$ obstructive sleep apnoea groups. a) Mucosa-predominant tissue. b) Musclepredominant tissue. IDV: individual density value; RANTES: regulated on activation, normal T-cell expressed and secreted; IL: interleukin; TGF: transforming growth factor; IFN: interferon. ${ }^{*}: p<0.05$

specimens, the connective tissue content within muscle fascicles was also analysed separately from connective tissue in regions surrounding muscle tissue.

\section{Statistical analysis}

Between-group comparisons were made using unpaired t-tests. Correlation analysis was performed using Pearson's product correlation. A p-value of $<0.05$ was used for statistical significance, while a Bonferroni-type correction was applied for multiple comparisons.

\section{RESULTS}

\section{Subject characteristics}

As shown in table 1, subject characteristics were similar in the two groups, while apnoea severity was significantly greater in the severe OSA group. Neither group had significant medical comorbities and medications were similar in the two groups.

\section{Cytokine mRNA expression}

Figure 1a shows that, while detectable levels of mRNA expression were present for all cytokines studied in the 

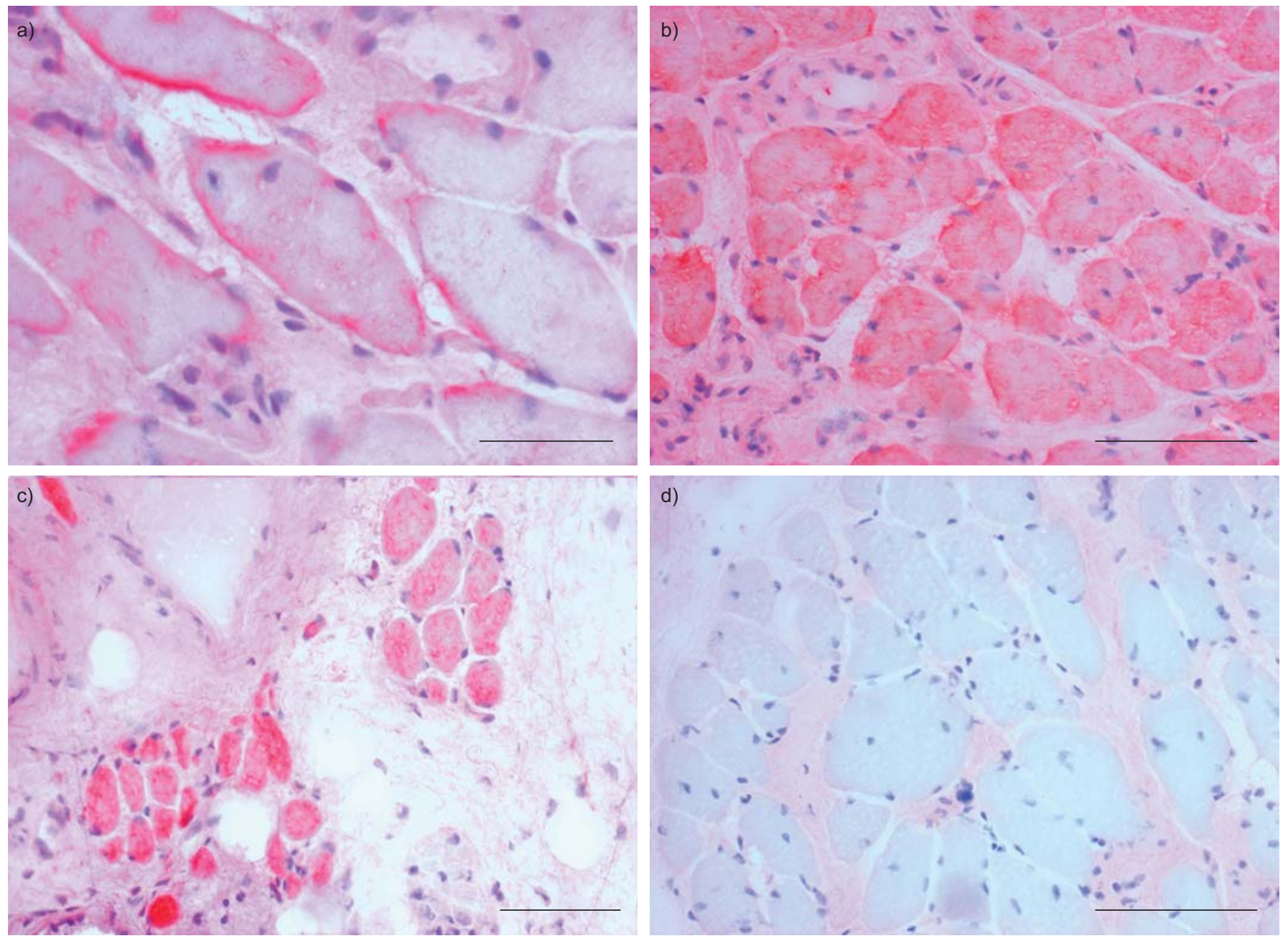

FIGURE 2. Immunohistochemical staining for interleukin-6. Unequivocal positive staining was localised to myocytes, while some areas of subepithelial connective tissue also appeared positive. The immunostaining pattern of myocytes was either a) peripheral (scale bar $=50 \mu \mathrm{m}$ ) or b, c) diffuse (scale bars $=100 \mu \mathrm{m}$ ). Both patterns could be observed within the same section. d) Absence of myocyte staining when using an irrelevant isotype-matched negative control antibody (scale bar=100 $\mu \mathrm{m}$ ).

mucosa-predominant compartment for both mild and severe OSA groups, the group mean values for IL- $1 \alpha$, IL- 6 and TGF- $\beta$ were significantly higher in the severe versus mild OSA subjects. A different pattern was observed in the musclepredominant compartment, where RANTES expression was significantly higher for severe OSA patients, while IL- $1 \alpha$, IL- 6 and TGF- $\beta$ were not significantly different between the two groups (fig. 1b).

Correlation analyses were performed between polysomnographic measures of respiratory event frequency, duration and $\mathrm{O}_{2}$ desaturation, and cytokine expression in both mucosa- and muscle-predominant tissue. A positive correlation was identified between TGF- $\beta$ mRNA levels in mucosa-predominant tissue and apnoea/hypopnoea index (AHI) $(r=0.54 ; p=0.01)$. No other significant correlations were identified.

\section{Immunohistochemistry}

Increased IL-6 expression has been shown to occur within skeletal muscle in association with increased muscle usage [29], while TGF- $\beta$ upregulation is closely linked with tissue fibrosis in several diseases [30,31]. Therefore, immunocytochemistry was performed for these two prototypical cytokines, as shown in figures 2 and 3. IL-6 staining was primarily localised to muscle fibres in either a peripheral subsarcolemmal or diffuse pattern (fig. 2). In addition, some areas of subepithelial connective tissue also appeared to demonstrate positive immunoreactivity for IL-6, although this was not a consistent finding. As shown in figure 3, positive staining for TGF- $\beta$ was localised to the cytoplasm of mononuclear inflammatory cells. In mucosapredominant sections, these TGF- $\beta$-positive cells were observed in the subepithelial connective tissue as well as in deeper connective tissue layers. Within the muscle-predominant specimens, TGF- $\beta$-positive mononuclear cells were seen in the connective tissue both around and within muscle fascicles.

\section{Connective tissue}

In order to determine the amount of connective tissue present within upper airway tissue specimens, van Gieson staining was performed. Representative van Gieson-stained sections are shown in figure 4 and group mean data are shown in figure 5. In both mucosa- and muscle-predominant specimens, there was significantly more connective tissue in severe OSA 

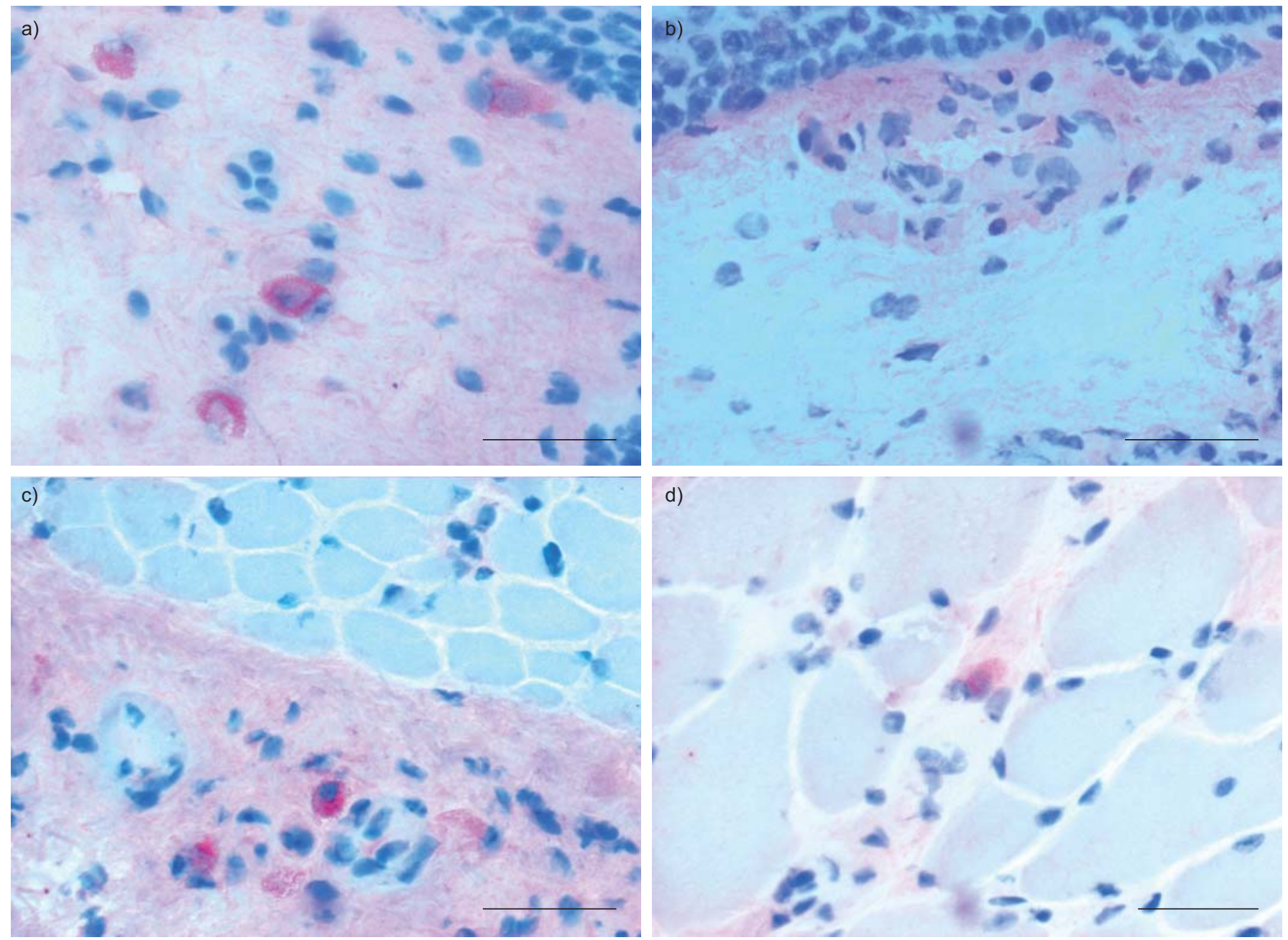

FIGURE 3. Immunohistochemical staining for transforming growth factor- $\beta$. Positive staining was localised to the cytoplasm of inflammatory cells. a) Staining of cells in the subepithelial connective tissue layer in a mucosa-predominant specimen (scale bar $=50 \mu \mathrm{m}$ ). b) Absence of staining in the same patient with isotype-matched negative control antibody (scale bar $=50 \mu \mathrm{m}$ ). In muscle-predominant sections, positively staining inflammatory cells were also seen in connective tissue c) surrounding (scale bar $=100 \mu \mathrm{m})$ or $d$ ) within muscle fascicles (scale bar $=50 \mu \mathrm{m}$ ).

subjects. For muscle-predominant specimens, within-fascicle connective tissue content was not significantly different between the two OSA groups, while connective tissue outside muscle fascicles (analogous to mucosa-predominant connective tissue) was significantly increased in severe OSA. Counts for other tissue elements, including mucous glands, blood vessels and muscle content were not significantly different between the two groups. For the two groups combined, a positive correlation was identified between connective tissue content in mucosa-predominant tissue and AHI $(r=0.45$; $\mathrm{p}=0.04)$. No other significant correlations were identified.

\section{Detection of protein carbonylation}

For both mucosa- and muscle-predominant specimens, there was evidence for increased oxidative modification (carbonylation) of upper airway tissue proteins in the severe OSA group. This was revealed in the form of several prominent bands, with molecular weights of $\sim 26, \sim 39$ and $\sim 68 \mathrm{kDa}$ (fig. 6). As illustrated in figure 7 , the changes were significantly different between mild and severe OSA subjects for the 26- and 68-kDa protein bands in mucosa-predominant specimens, and for all three molecular weight species in muscle-predominant specimens.

\section{DISCUSSION}

Several studies have demonstrated increased inflammation in the upper airway in OSA [4, 11, 12]. SERIES et al. [12] reported increased CD4+ and CD8+ lymphocytes and macrophages in uvular tissue from the morbidly obese, but not nonobese OSA patients compared with snoring controls. We recently compared inflammatory cells within mucosal and muscular compartments of upper airway specimens from OSA patients and nonapnoeic controls of similar body mass index (BMI) [4]. OSA patients had significantly more activated (CD25+) T-cells within both compartments, but with differing T-cell populations in the muscular (CD4+) versus mucosal (CD8+ and CD4+) compartments. These findings suggest that inflammation within these two compartments may be regulated by different pro-inflammatory mediators in OSA.

There is currently little published data on upper airway tissue cytokine expression in adult OSA. LOUBAKI et al. [32] reported 



FIGURE 4. Photomicrographs of representative van Gieson-stained sections. a) Mucosa-predominant tissue specimen with counting grid over subepithelial area. In this particular image, $85 \%$ of counts fell on stained connective tissue (scale bar $=150 \mu \mathrm{m})$. b) Muscle-predominant specimen illustrating connective tissue staining within muscle fascicles and in the surrounding tissue (scale bar $=200 \mu \mathrm{m}$ ).

that tumour necrosis factor (TNF)- $\alpha$ levels are increased in uvular muscle tissue from obese OSA patients compared with both nonobese OSA patients and controls. Unfortunately, that study had no obese, non-OSA controls to clarify the role of obesity. In our study, the mild and severe OSA groups were well-matched for BMI (with mean BMI closest to the nonobese OSA subjects in the study by LOUBAKI et al. [32]), yet we found significant differences in cytokine levels between the mild and severe groups.

The cytokines we selected in this study modulate leukocyte trafficking, tissue repair and fibrosis. RANTES is a chemoattractant for inflammatory cells, including CD4+ lymphocytes, and is upregulated in skeletal muscle cells by pro-inflammatory cytokines, including TNF- $\alpha$, IL- $1 \alpha$ and IFN- $\gamma$ [33]. L-selectin is an adhesion molecule involved in leukocyte migration into injured tissues [34]. In vivo, expression of RANTES and other $\mathrm{C}-\mathrm{C}$ chemokines increases greatly after skeletal muscle injury [33, 35]. In addition, cellular receptors for RANTES are found on both leukocytes and myoblasts,

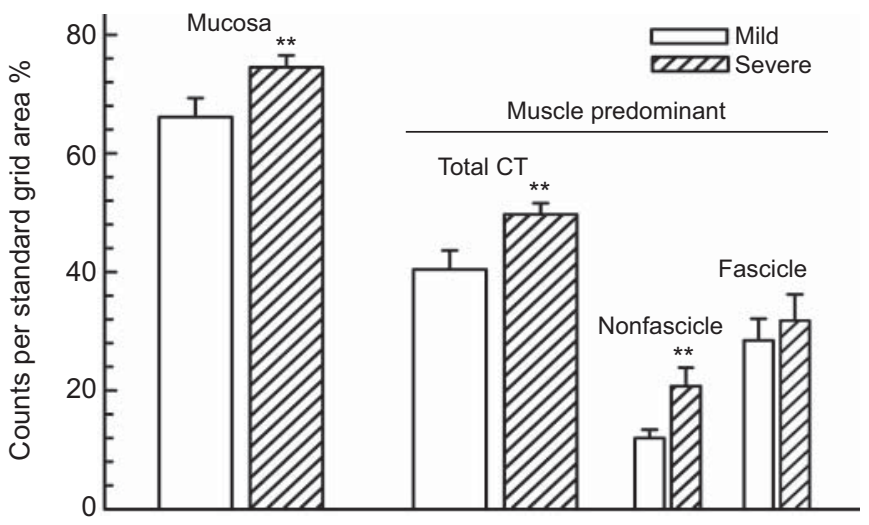

FIGURE 5. Group mean $\pm \mathrm{SE}$ for connective tissue counts in van Giesonstained mucosa- and muscle-predominant sections. Mucosal specimens: mild $(n=10)$; severe $(n=17)$. Muscle specimens: mild $(n=8)$; severe $(n=10) .{ }^{* *}: p<0.01$. suggesting that RANTES may influence muscle regeneration [35]. Thus, our finding of increased RANTES expression in severe versus mild OSA could be consistent with increased upper airway muscle loading, injury and repair in severe OSA.

To our knowledge, expression of IL-6 has not previously been demonstrated in upper airway muscles of OSA patients. IL-6 production by skeletal muscle is a well-recognised normal response to loading and exercise [29]. Thus, our finding of IL-6 expression within muscle fibres of both groups is again consistent with loading of upper airway muscles, although we did not find significant differences between mild and severe OSA.

TGF- $\beta$ has anti-inflammatory properties and is a prototypical pro-fibrotic cytokine that plays a key role in post-inflammatory fibrosis [30, 31]. In our study, TGF- $\beta$ expression was upregulated in severe versus mild OSA, with immunohistochemical findings suggesting that inflammatory cells were the primary source. IL- $1 \alpha$ and IL- 6 can also promote fibrosis, whereas IFN- $\gamma$ is generally considered to have anti-fibrotic

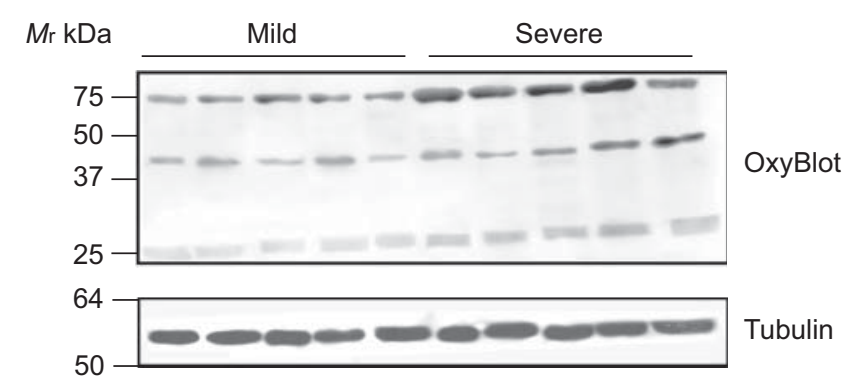

FIGURE 6. Representative immunoblot for carbonylated proteins (OxyBlot Protein Oxidation Detection; Invitrogen Inc., Purchase, NJ, USA) from musclepredominant samples, indicating the presence of carbonylated protein bands, which are increased in the severe obstructive sleep apnoea group. Equal protein loading between lanes was verified using $\alpha$-tubulin as a reference protein standard. Mr: relative molecular mass. 

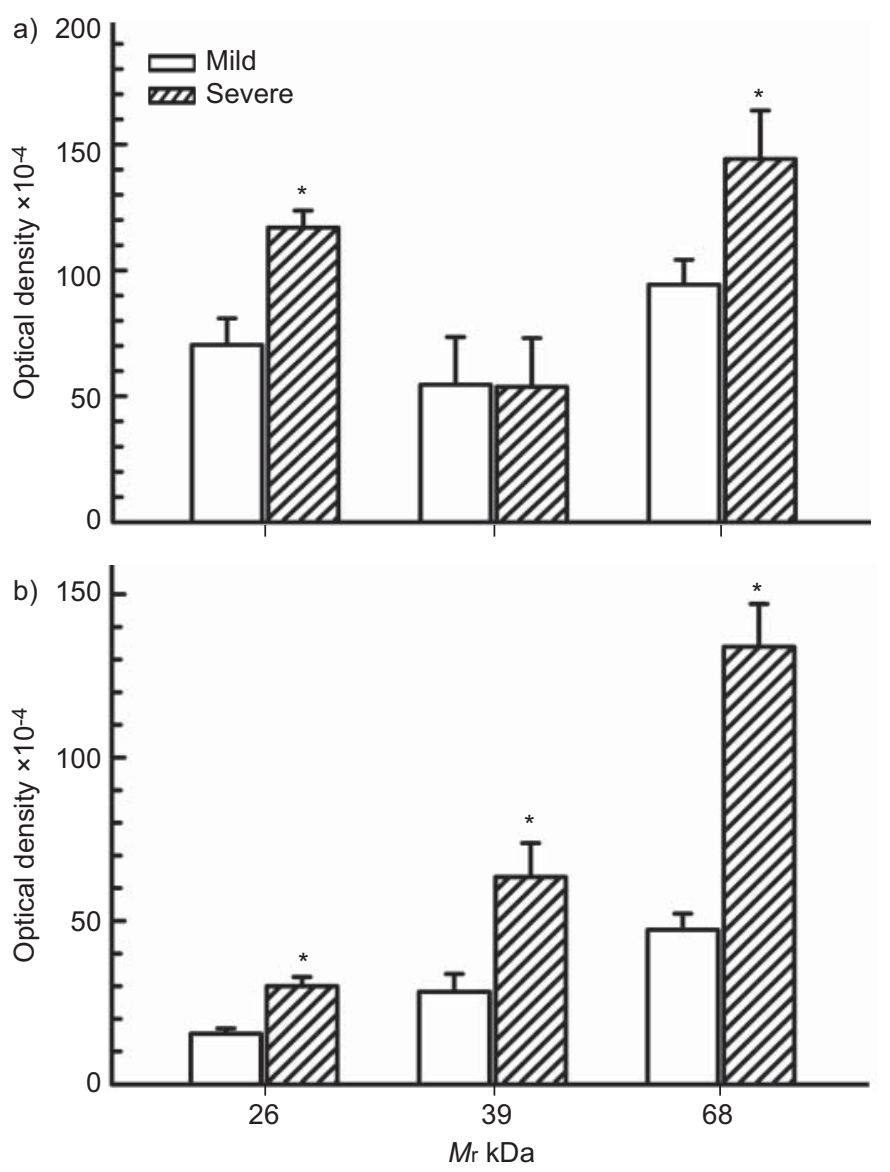

FIGURE 7. Group mean \pm SE optical density for carbonylated protein bands in severe versus mild obstructive sleep apnoea subjects ( $n=5$ per group) for a) mucosa- and b) muscle-predominant tissues specimens. Mr: relative molecular mass. *: $p<0.05$

effects $[30,31]$. Therefore, our demonstration of a pro-fibrotic cytokine profile (i.e. significantly increased IL- $1 \alpha$, IL- 6 and TGF- $\beta$, but no increase in IFN- $\gamma$ ) in the mucosa in severe OSA is consistent with the greater upper airway connective tissue content observed in this group.

These findings suggest that ongoing inflammation and repair may lead to a form of upper airway remodelling with increased tissue connective tissue deposition in severe OSA. Previous studies have reported increased [17, 18] or unchanged [11] upper airway mucosal connective tissue in OSA. Disorganisation of the elastic fibrillar network in uvular mucosa in severe OSA has also been described [12]. In upper airway muscles, OSA has been associated with increased connective tissue in the English bulldog [36], and in human palatal [19] and pharyngeal constrictor [20], but not in uvular [37] or genioglossus [37, 38], muscles. The differences in findings between studies are probably due to variations in OSA severity, tissue sampling and the techniques applied to assess connective tissue characteristics.

Increased fibrosis within upper airway tissue could affect airway patency in several ways. Connective tissue deposition could contribute to increased wall thickness and reduced intraluminal cross-sectional area. Fibrosis could also impede mechanical coupling between upper airway contractile and noncontractile elements. Indeed, SERIES et al. [21] showed that equivalent intensities of stimulated muscle contraction produced less uvular tissue displacement in OSA than normal subjects [21]. Furthermore, upper airway collapsibility could be adversely affected, in that analysis of tissue changes following oropharyngeal laser procedures suggests that excessive connective tissue responses are associated with OSA worsening [39].

Another potential source of upper airway dysfunction in OSA is increased oxidative stress. Increased inflammation and recurrent hypoxia-reoxygenation are both potential sources of increased oxidative stress in OSA $[6,40]$. Nuclear factor-кB, which is a key transcription factor upregulated in intermittent hypoxia $[6,40]$, has potent pro-inflammatory effects, upregulating cytokines, such as IL-1 $\alpha$, IL-6 and RANTES [41]. Thus, the pro-inflammatory cytokine profile observed in our tissues, while not specific, is consistent with a response to increased oxidative stress. Moreover, our demonstration of increased carbonyl modification of proteins within the upper airway tissues is consistent with this scenario [28]. Reactive oxygen species have a well-established ability to impair skeletal muscle force-generating capacity [15, 16], and could also adversely affect upper airway function by contributing to previously described upper airway neuropathy [5].

Several limitations of our study should be acknowledged. In particular, use of clinical specimens precluded our studying three potentially important groups: nonobese, nonapnoeic normal subjects and morbidly obese subjects, both nonapnoeic and apnoeic. We were unable to identify nonapnoeic individuals among patients undergoing upper airway surgical intervention and could not ethically biopsy tissue of this magnitude from normal subjects. Morbidly obese patients rarely undergo upper airway surgery at our institution. Thus, while clear differences emerged between mild and severe OSA patients in our study, it may be that cytokine expression in mild OSA subjects would also differ from normal subjects and/or that morbidly obese subjects would show even greater inflammation. Other tissue sampling techniques and/or validation of noninvasive measures will be required to address these possibilities. Other limitations of our study are that immunostaining provides localisation data but is difficult to quantify $[42,43]$ and that only a small minority of our subjects were female, so that potential sex differences could not be addressed.

In summary, we have demonstrated that severe OSA is associated with increased expression of several pro-inflammatory and/or pro-fibrotic cytokines within the mucosal and muscular compartments of upper airway tissue, with a concomitant increase in connective tissue deposition. To our knowledge, we also show the first evidence for increased oxidative stress within the upper airway muscles in severe OSA. The extent to which these abnormalities contribute to upper airway dysfunction in OSA, and their relationship with systemic and other tissue inflammatory changes in this condition remain to be determined. However, it seems likely that these alterations would affect upper airway mechanics and function. 


\section{SUPPORT STATEMENT}

This study was supported by Canadian Institutes of Health Research (grant number MOP-53120), the Fonds de la Recherche en Santé du Québec, and the Montreal Chest Institute and McGill University Health Centre Research Institutes.

\section{STATEMENT OF INTEREST}

None declared.

\section{ACKNOWLEDGEMENTS}

The authors express their gratitude to M. Black, M. Heier, K. Kost, S. Frenkiel and A. Zeitouni (all Dept of Otolaryngology, McGill University, Montreal, QC, Canada) for contributing surgical specimens, and to the polysomnography technologist staff of the McGill University Health Centre Sleep Laboratory (Montreal) for their contributions to sleep recordings. We also thank J. Bourdon, D. Gvozdic, S. Al-Mot and E. Schotman (Meakins-Christie Laboratories, McGill University, Montreal) for invaluable technical assistance.

\section{REFERENCES}

1 Bergeron C, Kimoff J, Hamid Q. Obstructive sleep apnea syndrome and inflammation. J Allergy Clin Immunol 2005; 116: 1393-1396

2 Arnardottir ES, Mackiewicz M, Gislason T, et al. Molecular signatures of obstructive sleep apnea in adults: a review and perspective. Sleep 2009; 32: 447-470.

3 Rubinstein I. Nasal inflammation in patients with obstructive sleep apnea. Laryngoscope 1995; 105: 175-177.

4 Boyd JH, Petrof BJ, Hamid Q, et al. Upper airway muscle inflammation and denervation changes in obstructive sleep apnea. Am J Respir Crit Care Med 2004; 170: 541-546.

5 Payne RJ, Kost KM, Frenkiel S, et al. Laryngeal inflammation assessed using the reflux finding score in obstructive sleep apnea. Otolaryngol Head Neck Surg 2006; 134: 836-842.

6 Lavie L. Obstructive sleep apnoea syndrome: an oxidative stress disorder. Sleep Med Rev 2003; 7: 35-51.

7 Depalo A, Carpagnano GE, Spanevello A, et al. Exhaled NO and iNOS expression in sputum cells of healthy, obese and OSA subjects. J Intern Med 2008; 263: 70-78.

8 Carpagnano GE, Kharitonov SA, Resta O, et al. Increased 8isoprostane and interleukin- 6 in breath condensate of obstructive sleep apnea patients. Chest 2002; 122: 1162-1167.

9 Devouassoux G, Levy P, Rossini E, et al. Sleep apnea is associated with bronchial inflammation and continuous positive airway pressure-induced airway hyperresponsiveness. I Allergy Clin Immunol 2007; 119: 597-603.

10 Salerno FG, Carpagnano E, Guido P, et al. Airway inflammation in patients affected by obstructive sleep apnea syndrome. Respir Med 2004; 98: 25-28.

11 Paulsen FP, Steven $\mathrm{P}$, Tsokos $\mathrm{M}$, et al. Upper airway epithelial structural changes in obstructive sleep-disordered breathing. Am J Respir Crit Care Med 2002; 166: 501-509.

12 Series F, Chakir J, Boivin D. Influence of weight and sleep apnea status on immunologic and structural features of the uvula. Am J Respir Crit Care Med 2004; 170: 1114-1119.

13 Dempsey JA, Veasey SC, Morgan BJ, et al. Pathophysiology of sleep apnea. Physiol Rev 2010; 90: 47-112.

14 Wilcox P, Milliken C, Bressler B. High-dose tumor necrosis factor a produces an impairment of hamster diaphragm contractility. Am J Respir Crit Care Med 1996; 153: 1611-1615.

15 Reid MB. Free radicals and muscle fatigue: of ROS, canaries, and the IOC. Free Radic Biol Med 2008; 44: 169-179.

16 Dunleavy M, Bradford A, O'Halloran KD. Oxidative stress impairs upper airway muscle endurance in an animal model of sleepdisordered breathing. Adv Exp Med Biol 2008; 605: 458-462.
17 Woodson BT, Garancis JC, Toohill RJ. Histopathologic changes in snoring and obstructive sleep apnea syndrome. Laryngoscope 1991; 101: 1318-1322.

18 Berger G, Gilbey P, Hammel I, et al. Histopathology of the uvula and the soft palate in patients with mild, moderate, and severe obstructive sleep apnea. Laryngoscope 2002; 112: 357-363.

19 Lindman R, Stahl PS. Abnormal palatopharyngeal muscle morphology in sleep-disordered breathing. J Neurol Sci 2002; 195: 11-23.

20 Ferini-Strambi LJ, Smirne S, Moz U, et al. Muscle fibre type and obstructive sleep apnea. Sleep Res Online 1998; 1: 24-27.

21 Series F, Cote C, St Pierre S. Dysfunctional mechanical coupling of upper airway tissues in sleep apnea syndrome. Am J Respir Crit Care Med 1999; 159: 1551-1555.

22 Champagne K, Schwartzman K, Opatrny L, et al. Obstructive sleep apnoea and its association with gestational hypertension. Eur Respir J 2009; 33: 559-565.

23 Rechtschaffen A, Kales A. A Manual of Standardized Terminology, Technique and Scoring System for Sleep Stages of Human Sleep. Los Angeles, UCLA, 1968.

24 EEG arousals: scoring rules and examples: a preliminary report from the Sleep Disorders Atlas Task Force of the American Sleep Disorders Association. Sleep 1992; 15: 173-184.

25 Sleep-related breathing disorders in adults: recommendations for syndrome definition and measurement techniques in clinical research. The Report of an American Academy of Sleep Medicine Task Force. Sleep 1999; 22: 667-689.

26 Divangahi M, Demoule A, Danialou G, et al. Impact of IL-10 on diaphragmatic cytokine expression and contractility during Pseudomonas infection. Am J Respir Cell Mol Biol 2007; 36: 504-512.

27 Pepe C, Foley S, Shannon J, et al. Differences in airway remodeling between subjects with severe and moderate asthma. J Allergy Clin Immunol 2005; 116: 544-549.

28 Barreiro E, Gea J, Di FM, et al. Protein carbonyl formation in the diaphragm. Am J Respir Cell Mol Biol 2005; 32: 9-17.

29 Pedersen BK, Febbraio MA. Muscle as an endocrine organ: focus on muscle-derived interleukin-6. Physiol Rev 2008; 88: 1379-1406.

30 Venkatesan N, Roughley PJ, Ludwig MS. Proteoglycan expression in bleomycin lung fibroblasts: role of transforming growth factor$\beta_{1}$ and interferon- $\gamma$. Am J Physiol Lung Cell Mol Physiol 2002; 283: L806-L814.

31 Wynn TA. Cellular and molecular mechanisms of fibrosis. J Pathol 2008; 214: 199-210.

32 Loubaki L, Jacques E, Semlali A, et al. Tumor necrosis factor- $\alpha$ expression in uvular tissues differs between snorers and apneic patients. Chest 2008; 134: 911-918.

33 Demoule A, Divangahi M, Danialou G, et al. Expression and regulation of CC class chemokines in the dystrophic $(\mathrm{mdx})$ diaphragm. Am J Respir Cell Mol Biol 2005; 33: 178-185.

34 Kneuer C, Ehrhardt C, Radomski MW, et al. Selectins: potential pharmacological targets? Drug Discov Today 2006; 11: 1034-1040.

35 Yahiaoui L, Gvozdic D, Danialou G, et al. CC family chemokines directly regulate myoblast responses to skeletal muscle injury. J Physiol 2008; 586: 3991-4004.

36 Petrof BJ, Pack AI, Kelly AM, et al. Pharyngeal myopathy of loaded upper airway in dogs with sleep apnea. J Appl Physiol 1994; 76: 1746-1752.

37 Series F, Simoneau J-A, St. Pierre S, et al. Characteristics of the genioglossus and musculus uvulae in sleep apnea hypopnea syndrome and in snorers. Am J Respir Crit Care Med 1996; 153: 1870-1874.

38 Carrera M, Barbe F, Sauleda J, et al. Effects of obesity upon genioglossus structure and function in obstructive sleep apnoea. Eur Respir J 2004; 23: 425-429.

39 Berger G, Finkelstein Y, Ophir D. Histopathologic changes of the soft palate after laser-assisted uvulopalatoplasty. Arch Otolaryngol Head Neck Surg 1999; 125: 786-790. 
40 Ryan S, Taylor CT, McNicholas WT. Selective activation of inflammatory pathways by intermittent hypoxia in obstructive sleep apnea syndrome. Circulation 2005; 112: 2660-2667.

41 Demoule A, Divangahi M, Yahiaoui L, et al. Endotoxin triggers nuclear factor-kB-dependent up-regulation of multiple proinflammatory genes in the diaphragm. Am J Respir Crit Care Med 2006; 174: 646-653.
42 Cregger M, Berger AJ, Rimm DL. Immunohistochemistry and quantitative analysis of protein expression. Arch Pathol Lab Med 2006; 130: 1026-1030.

43 Taylor CR, Levenson RM. Quantification of immunohistochemistry: issues concerning methods, utility and semiquantitative assessment II. Histopathology 2006; 49: 411-424. 